\title{
A STUDY OF THERAPEUTIC RESPONSE AND ADVERSE EFFECTS OF INTRAVENOUS ERYTHROPOIETIN VERSUS SUBCUTANEOUS ERYTHROPOIETIN ON HEMODIALYSIS PATIENTS IN THE DEPARTMENT OF NEPHROLOGY OF OHRC
}

\author{
PARTHA SARADHI SV ${ }^{*}$, MIRZA MISBA ALI BAIG ${ }^{2}$, AMTUL IRFANA ${ }^{3}$, ARJUMAND KAUSER FARIHA ${ }^{3}$, \\ BUSHRA FATIMA ${ }^{3}$
}

${ }^{1}$ Consultant Nephrologist, Deccan College of Medical Sciences and Owaisi Hospital and Research center, Hyderabad, Telangana India, ${ }^{2}$ Department of Pharmacy Practice, Deccan School of Pharmacy, Hyderabad, Telangana India, ${ }^{3}$ Pharm D (PB) Students of Deccan School of Pharmacy, Hyderabad, Telangana India

Email: drparthanephro@gmail.com

Received: 30 Nov 2016 Revised and Accepted: 30 Jun 2017

\section{ABSTRACT}

Objective: To study the efficacy of intravenous erythropoietin and subcutaneous erythropoietin in hemodialysis patients who have persistent anemia despite correction of iron therapy and to measure the outcomes in terms of raise in haemoglobin concentration and adverse events in both the groups.

Methods: After ethical committee approval the current study was conducted at the Department of Hemodialysis of Owasi Hospital and Research Centre, Hyderabad a period of 6 mo duration. 60 patients undergoing hemodialysis were recruited into out study who had haemoglobin less than 10.0 despite corrected iron levels. Patients were divided into two groups for intravenous administration and subcutaneous administration of alpha erythropoietin. Patients were stratified into three sub-groups of mild, moderate and severe anaemia. Therapeutic response was recorded in the form of monthly hemoglobin and hemoatocrit. Of the 30 patients in the subcutaneous group, erythropoietin was given to 19 males and 11 females, while intravenous erythropoietin was administered to 17 males and 13 females in the other 30 patients.

Results: The mean hemoglobin level in the subcutaneous group was 5.16 at the commencement of the study and in the intravenous group the mean hemoglobin was 5.0. In the subcutaneous group, the mean rise in the hemoglobin was rapidly achieved in 3 mo duration when compared to the intravenous group. Mean Systolic Blood pressure was higher in the intravenous group when compared to the subcutaneous group. Spillage of the drug was minimal in subcutaneous group when compared to the intravenous group.

Conclusion: After correction of the iron deficiency, low dose of erythropoietin subcutaneously promised to maintain expected hemoglobin level above $10 \mathrm{~g} / \mathrm{dl}$ with no adverse events compared to intravenous erythropoietin. Erythropoitin alpha at a dose of $4000 \mathrm{IU}$ was enough to achieve the therapeutic target of Hemoglobin>10.0 by administering subcutaneously accelerated hypertension was less when compared to Intravenous erythropieitn post dialysis. Hence we recommend to use erythropoietin subcutaneously rather than intravenously.

Keywords: Anemia, Erythropoietin, Hemodialysis, Hemoglobin, Intravenous, Subcutaneous

(c) 2017 The Authors. Published by Innovare Academic Sciences Pvt Ltd. This is an open access article under the CC BY license (http://creativecommons.org/licenses/by/4.0/) DOI: http://dx.doi.org/10.22159/ijpps.2017v9i8.16409

\section{INTRODUCTION}

Chronic kidney disease is a global health problem rising across the world due to diabetes and hypertension. End stage renal disease is associated with multiple problems like anemia, volume overload and increased risk of death.

According to Kidney Disease: Improving Global Outcomes (KDIGO), Chronic Kidney Disease (CKD) is defined as kidney damage for more than 3 mo, resulting in structural and functional abnormalities of the kidney function with or without decreased GFR $<60 \mathrm{ml} / \mathrm{min} / 1.73 \mathrm{~m}^{2}$ for more than $3 \mathrm{mo}$, with or without kidney damage [1].

The World Health Organization (WHO) defines anemia as hemoglobin $(\mathrm{Hgb})$ concentration below $13.0 \mathrm{~g} / \mathrm{dl}$ for adult men and below $12.0 \mathrm{~g} / \mathrm{dl}$ for mature women [2]. Renal anemia is a major complication in patients with chronic kidney disease, particularly dialysis patients. The prevalence of anemia increases from $1 \%$ in patients with an eGFR of $60 \mathrm{ml} / \mathrm{mil} / 1.73 \mathrm{~m}^{2}$ (stage III CKD) to $9 \%$ at an eGFR rate of $30 \mathrm{ml} / \mathrm{min} / 1.73 \mathrm{~m}^{2}$ (stage IV CKD) and to $33 \%$ for men and $67 \%$ for women at an eGFR of $15 \mathrm{ml} / \mathrm{min} / 1.73 \mathrm{~m}^{2}$ (Stage V CKD) [3]. Anemia enhances the mortality with cardiovascular illness, left ventricular hypertrophy and congestive heart failure. Correction of anemia is essential and the target hemoglobin up to $12 \mathrm{~g} / \mathrm{dl}$ helps in regressing the heart failure [4].

The causes of anemia in Chronic Kidney Disease (CKD) are multifactorial, due to relative erythropoietin deficiency, iron deficiency, blood loss, chronic inflammation, and circulating inhibitors of erythropoiesis [5]. $10 \%$ of the total population worldwide is affected by CKD and millions die each year because they cannot afford the treatment [6]

Currently, approximately 2 million people in the world are receiving the treatment with hemodialysis or a kidney transplant for a healthy living [7]. Administration of erythropoietin after achieving good iron stores stabilizes the hemoglobin synthesis from the marrow. Different types of erythropoietin are available and comparative study had been performed in different routes for the achievement of target hemoglobin.

The recommended target hemoglobin in all stage 5 CKD patients receiving Erythropoietin Stimulating Agents (ESA) is 11-12 g/dl. The findings from Cardiovascular Reduction early Anemia Treatment Epoetin beta (CREATE), The Correction of Hemoglobin and Outcomes in Renal Insufficiency (CHOIR), and Trial to Reduce Cardiovascular Events with Aranasep Therapy (TREAT) support the recommendation of adhering to the Hemoglobin level not exceeding $12 \mathrm{~g} / \mathrm{dl}[8]$

Data on Indian patients have been done but consensus on the route of administration has not been found in the literature. In the present study, we have therefore compared the therapeutic response and adverse effects of intravenous alpha erythropoietin and 
subcutaneous alpha erythropoietin on hemodialysis patients in a fixed dose.

\section{MATERIALS AND METHODS}

\section{Methods}

60 patients were divided into 2 equal groups receiving subcutaneous erythropoietin (group A) and intravenous erythropoietin (group B) at a dose of 4000 units per session. They were again classified into 3 sub-groups depending upon hemoglobin criteria i.e. mild anemia (group I), moderate anemia (group II) and severe anemia (group III). After iron correction, erythropoietin was administered equally in subcutaneous group and intra-venous group.

\section{Data analysis}

Demographic data including age, sex, name, religion and renal history, duration of CKD, initiation and maintenance of hemodialysis and date of enrolment in dialysis were considered. In addition, we recorded antihypertensive medication that was taken, the frequency of iron therapy and erythropoietin duration. Therapeutic response was monitored monthly by checking hemoglobin levels and serum creatinine was recorded. Serial monitoring of pre and post hemodialysis blood pressure was recorded and any adverse events were marked.

\section{Statistical analysis}

The data collected was analyzed. Descriptive statistical analysis has been carried out using MS Word tables, the level of significance was set at $5 \% \quad(\mathrm{p}<0.005)$ with $95 \%$ confidence interval. The chi-square test was applied and all statistical calculation was carried out with open Epi: A web-based epidemiological and statistical calculator. Outcomes on continuous measurement are presented with Mean and results on categorical measurement are presented in number (\%).

\section{RESULTS}

\section{Characteristics of study participants}

Out of 60 patients, males and females were 60\% and $40 \%$ respectively. In a subcutaneous group, $63 \%$ patients were males and $37 \%$ patients were females. In an intravenous group, $57 \%$ patients were males and $43 \%$ patients were females.

\section{Categorization of patients based on age group}

Among 60 patients, they were $10 \%$ patients who were in age group of $19-29$ y; $26.66 \%$ patients in the age group of $30-39 y$; $15 \%$ patients in the age group of $40-49 \mathrm{y} ; 23.33 \%$ patients in the age group of $50-59 \mathrm{y}, 18.33 \%$ patients in the age group of $60-69 \mathrm{y}$ and $6.66 \%$ patients in the age group of 70-79 $\mathrm{y}$.

\section{Categorization of patients based on duration of dialysis}

Among 60 patients, they were $40 \%$ patients who were undergoing dialysis since few months, $15 \%$ patients since $1 \mathrm{y}, 18.33 \%$ patients since $2 \mathrm{y}, 11.66 \%$ patients since $3 \mathrm{y}, 5 \%$ patients since $4 \mathrm{y}$ and $10 \%$ patients for more than $5 \mathrm{y}$.

\section{Categorization of patients based on iron therapy}

Among 60 patients, $75 \%$ patients received iron therapy before erythropoietin administration and $25 \%$ patients did not receive iron therapy because their TSAT was above 30\%. Transferrin saturation (TSAT) of 20\% is recommended in KDIGO guidelines for patients with CKD and End Stage Renal Disease below which iron therapy is indicated [9].

\section{Observation}

The Group A patients who received subcutaneous erythropoietin showed an increase in hemoglobin value throughout the study. The group-I patients mean $\mathrm{Hgb}$ level was $5.16 \mathrm{~g} / \mathrm{dl}$ in the initial stage of study whereas there was no patient found whose Hgb level was below $6 \mathrm{~g} / \mathrm{dl}$ at the end of the study. The group-II patients mean Hgb level was $8.8 \mathrm{~g} / \mathrm{dl}$ in the commencement of the study, which increased to $9.0 \mathrm{~g} / \mathrm{dl}$ in the final stage of the study. The group-III patients mean $\mathrm{Hgb}$ level was $10.5 \mathrm{~g} / \mathrm{dl}$ in the initial stage of study which gradually rose to $11.14 \mathrm{~g} / \mathrm{dl}$ till the end of study period.

\section{Observation}

The mean Hgb level of group-I patients from the intravenous group was $5.0 \mathrm{~g} / \mathrm{dl}$ in the initial stage of study and $5.5 \mathrm{~g} / \mathrm{dl}$ at the goal of the study. The group-II patients mean Hgb level was $7.8 \mathrm{~g} / \mathrm{dl}$ in the commencement of the study and increased to $8.7 \mathrm{~g} / \mathrm{dl}$ till the last month of study. The group-III patients mean Hgb level was $11.2 \mathrm{~g} / \mathrm{dl}$ in the initial stage of study and increased to $10.5 \mathrm{~g} / \mathrm{dl}$ till the conclusion of the study.

Table 1: Month-wise hemoglobin mean values of subcutaneous erythropoietin in group-A

\begin{tabular}{llll}
\hline Months & Group-I Mean Hgb<6 g/dl & Group-II Mean Hgb 6-10 g/dl & Group-III Mean Hgb 10-12 g/dl \\
\hline October & 5.16 & 8.3 & 10.5 \\
November & 6.0 & 8.5 & 10.9 \\
December & 0 & 8.8 & 11.0 \\
January & 0 & 9.0 & 11.11 \\
February & 0 & 9.0 & 11.14 \\
\hline
\end{tabular}

Table 2: Month-wise hemoglobin mean values of intravenous erythropoietin in group-B

\begin{tabular}{llll}
\hline Months & Group-I Mean Hgb<6 g/dl & Group-II Mean Hgb 6-10 g/dl & Group-III mean Hgb 10-12 g/dl \\
\hline October & 5.0 & 7.8 & 11.2 \\
November & 4.8 & 8.0 & 10.8 \\
December & 4.5 & 8.1 & 10.7 \\
January & 5.0 & 8.1 & 10.5 \\
February & 5.0 & 8.7 & 10.5 \\
\hline
\end{tabular}

In our study, the response of subcutaneous erythropoietin was good when compared to intravenous administration. The target hemoglobin was achieved more easily in the subcutaneous group compared to the intravenous group.

Thus, the present study showed that subcutaneous erythropoietin administration in a dose of 4000 units per session in patients on twice or thrice weekly dialysis is more effective in elevation of hemoglobin than intravenous administration of erythropoietin. No adverse effects were encountered throughout the study period.

\section{DISCUSSION}

In the current study, there was a significant elevation in the mean hemoglobin levels with respect to the fixed dose of 4000 units per session over the subcutaneous and intravenous route which demonstrated that the increase in hemoglobin levels was substantially high in the subcutaneous group over a period of 6 mo duration. This is comparable to study conducted by Eschbach et al. in 25 patients in CKD stage, 5 hemodialysis wherein the mean $\mathrm{Hgb}$ was greater at dose dependent manner in epo range between 15- 
500 units per kg body weight and requirement of blood transfusion was lesser in the higher dose group. Higher dose of epo was associated with a rise in blood pressure and increased creatinine levels and potassium levels [4].

In another study, Barclay et al. who compared the efficacy of low dose epo SC versus IV epo, they concluded that there was no difference in the therapeutic response of rise in hemoglobin in epo response between intravenous routes versus subcutaneous route [10].

In patients who received erythropoietin therapy subcutaneously with steady improvement in hemoglobin status, the work performance of the individuals increased and SF 36 score was higher among the patients with hemoglobin level greater than $10.0 \mathrm{~g} / \mathrm{dl}$. This can be compared to study done by Donald S. Silverberg et al. from Tel Aviv, Israel who found that patients with mild anemia with congestive heart failure and renal failure received recombinant erythropoietin therapy were found to have better performance in functional class symptoms both in nondiabetic and diabetic subjects [11].

In our study, the hemotocrit and hemoglobin levels got elevated sustainedly. In a study conducted by Besarab et al. regarding the cost efficacy of giving erythropoietin by subcutaneous route versus intravenous route, it was found that low dose erythropoietin was associated with significant improvement in hematocrit levels when compared to intravenous route [12].

In our study, a steep increase in hemoglobin was seen from third month onwards in the subcutaneous group when compared to intravenous group and there was no drop in the hemoglobin levels. Moreover, the subjects who attained Hgb concentration greater than $10.0 \mathrm{~g} / \mathrm{dl}$ were maintained on the $\mathrm{Hb}$ levels and did not require frequent dosage when compared to intravenous subjects. The loss of medication was less in the subcutaneous group when compared to the intravenous group. No rise in systolic or diastolic blood pressure was seen in the subcutaneous group but in the intravenous group, a 10\% rise in Systolic blood pressure was noted and none of them had any adverse vascular event. This can be comparable to the study conducted by James S. kaufman et al. Subcutaneous administration of erythropoietin in hemodialysis patient maintained the hematocrit in desired target range, with average weekly low dose of erythropoietin that is lower than compared to intravenous administration [13] Pharmaceutical dispensing of the drug with insulin syringes was effective for good absorption with no spillage, ease of administration, and avoidance of needle prick injury and economically efficacious.

\section{LIMITATION}

The sample size was small and we used only one brand of erythropoietin (Alpha epo). Compliance of patients with iron profile every 3 mo cannot be done. Illiteracy of the patients.

\section{ACKNOWLEDGEMENT}

We would like to thank all the patients with whose support and encouragement made this study possible. We would also like to thank Mirza Misba Ali Baig, Asst. professor, and resident doctors of the nephrology department for their help and guidance. We also thank the Arogyasri health care trust for cashless therapy for the patients.

\section{AUTHOR CONTRIBUTOR}

Dr. Partha Saradhi was the principal clinical guide and contributed to the aims, objectives materials and methods abstract. Dr. Mirza Ali Baig was the pharmacy guide and overall supervisor who contributed to the results and conclusions of the manuscript. Dr. Amtul Irfana and Dr. Bushra were active in preparing the data analysis and Dr. Kausar Fariha contributed the tables and references.

\section{CONFLICT OF INTERESTS}

There is no conflict of interest

\section{REFERENCES}

1. National Kidney Foundation. K/DOQI clinical practice guidelines for chronic kidney disease: evaluation, classification, and stratification. Am J Kidney Dis 2002;39:S1.

2. Kidney Disease: Improving global outcomes (KDIGO) anemia work group: kdigo clinical practice guideline for anemia in chronic kidney disease. Kidney Int Suppl 2012;2:279-335.

3. KDOQI. Clinical practice guideline and clinical practice recommendations for anemia in chronic kidney disease: 2001 update of hemoglobin target. Am J Kidney Dis 2007;50:471530.

4. Eschbach JW, Egrie JC, Downing MR, Browne JK, Adamson JW. Correction of the anemia of end-stage renal disease with recombinant human erythropoietin. N Engl J Med 1987; 316:73-8.

5. Dmitrieva O, de Lusignan S, Macdougall IC. Association of anaemia in primary care patients with chronic kidney disease: a cross-sectional study of quality improvement in chronic kidney disease (QICKD) trial data. BMC Nephrol 2013;14:24.

6. World Kidney day: Chronic Kidney Disease. Global facts about kidney disease; 2015.

7. Couser WG, Remuzzi G, Mendis S, Tonelli M. The contributions of chronic kidney disease to the global burden of major noncommunicable diseases. Kidney Int Dec 2011;80:1258-70.

8. Pharmacotherapy-A Pathophysiologic approach. 8th edition. Joseph T. Dipiro, Robert L. Talbert; 2011. p. 798-804.

9. K/DOQI Clinical practice guidelines and clinical practice recommendations for anemia in chronic kidney disease in adults. Am J Kidney Dis 2006;47(Suppl 3):S11-S145.

10. PG Barclay, ER Fischer, DC Harris. Interpatient variation in response to subcutaneous versus intravenous low dose erythropoietin. Clin Nephrol 1993;40:277-80.

11. Donald S Silverberg, Dov Wexler, Miriam Blum, Joseph Z Tchebiner, David Sheps. The effect of correction of anaemia in diabetics and nondiabetics with severe resistant congestive heart failure and chronic renal failure by subcutaneous erythropoietin and intravenous iron. Nephrol Dialysis Transplantation 2003;18:141-6.

12. Besarab A, Reyes CM, Hornberger J. Meta-analysis of subcutaneous versus intravenous epoetin in the maintenance treatment of anemia in hemodialysis patients. Am J Kidney Dis 2002;40:439-46.

13. James S Kaufman, Domentic J Reda, Carill Fye, David S Goldfarb. Department of the veterans affairs cooperative study group on erythropoietin in hemodialysis patients. $\mathrm{N}$ Engl J Med 1998;339:578-83.

\section{How to cite this article}

- Partha Saradhi Sarvepalli. A study of therapeutic response and adverse effects of intravenous erythropoietin versus subcutaneous erythropoietin on hemodialysis patients in the department of nephrology of OHRC. Int J Pharm Pharm Sci 2017;9(8):151-153. 